\title{
STATE OF THE ART DIGITAL ON-BOARD-ELECTRONICS VS. POTENTIALLY DISRUPTIVE CONTROL ARCHITECTURES FOR HYDRAULIC VALVES
}

\author{
Achim Richartz \\ Bosch Rexroth AG, Partensteiner Strasse 23, 01069 Dresden \\ Tel.: +49 9352 183314; E-mail address: achim.richartz@boschrexroth.de
}

\begin{abstract}
Currently discussed trends and new technologies regarding cloud or edge computing imply that even most recent designs and functionalities of digital on-board-control electronics may be outdated and eventually will totally disappear. Additionally, those new technologies attract potential users by promises like new use cases e.g. predictive maintenance or a simplified architecture and reduced installation efforts. On the other hand, automation levels and subsequent requirements are often mixed up or discussed too generally. Nevertheless, what is the rue situation today and in the upcoming years? This paper elaborates the potentials of both approaches - state of the art on-board-control electronics and potentially disruptive control architectures for hydraulic valves in order to take the right decision and reflect the pros and cons for each topology by:

Architecture of automation: In Terms of strongly hierarchical or multidimensional connected systems.

Requirement of installation: By reflecting the dedicated ecosystems, on levels like plant, machine, subsystems.

Maturity of technology: Looking on the user's perspective.

Safety and security: From legal and conformity aspects.

Performance needs by specific task: In comparing standard to demanding real life applications.

Keywords: digital on-board-electronics, hydraulic valves, control architectures
\end{abstract}

\section{INTRODUCTION}

The Bosch Rexroth AG is for sure known as one of the leading manufacturers of hydraulic control components such as proportional valves or electrohydraulic controlled pump systems. While todays widely used analogue electronics still perform well in many applications, they are limited functionality and connectivity. While analogue electronics by technology have "built in real time performance", first digital controllers sometimes suffered from performance lags. Today's state of the art generations crossed that bridge. Cycle times below $0.1 \mathrm{~ms}$ are the required standard and met. Performing as required, mostly Ethernet-Based solutions are implemented since years in industrial and mobile applications. With upcoming technical possibilities of connectivity solutions, the question is: Will edge or cloud based systems replace those existing solutions?

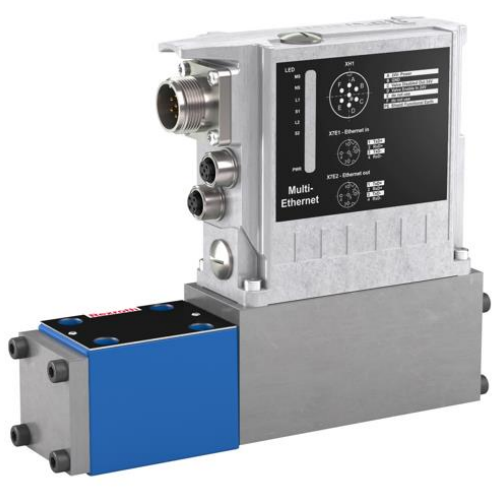

Figure 1: Bosch Rexroth servo solenoid directional control valve with IFB technology (IFB= integrated field bus) with Multi Ethernet communication. 


\section{ARCHITECTURE OF AUTOMATION}

Side a side the architectural differences between todays majority of industrial automation architectures are obvious. Key difference is an additional IT infrastructure to manage data exchange to e.g. a cloud.

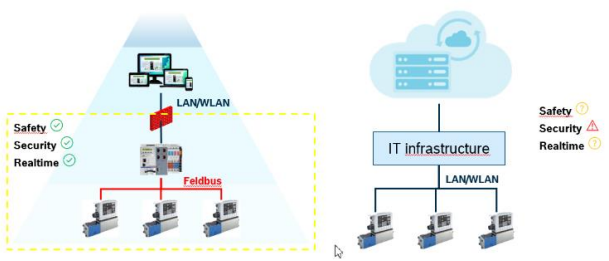

Figure 2: Architecture comparison; hierarchical vs. cloud connected

While Fieldbus based architectures show solved solutions for safety, security and real time already today, a fully installed LAN or WLAN installation mostly lags those requirements.

\section{REQUIREMENTS OF INSTALLATION}

As can be seen clearly from figure 2 , a very much different installation is required. As Ethernet based field busses are today's standard solutions, new other than today's IT-Infrastructure's need to be installed and maintained. This also leads to other competences for setup respectively commissioning and maintenance. While bigger companies with own IT departments may have these resources, small and mid size companies may have to install that or buy for that from external.

\section{MATURITY OF TECHNOLOGY}

Wireless and well-proven installations of full compliance can be found today in fun industry applications. Requirements there are demanding, even safety of humans for different SIL levels are in place, but for real time, this is not the case today.

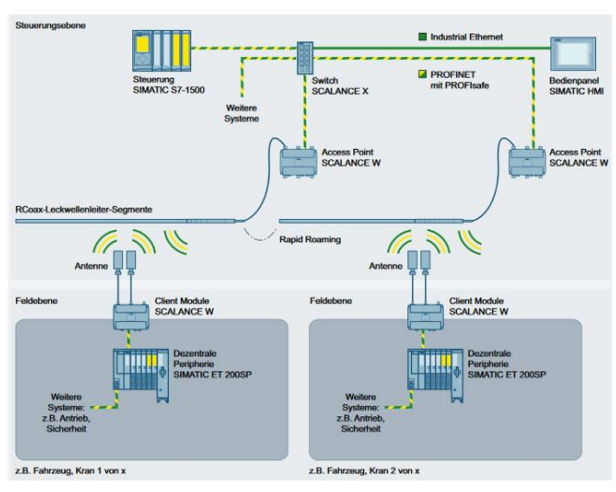

Figure 4: Bosch Rexroth servo solenoid directional control valve with IFB technology (IFB= integrated field bus) with Multi Ethernet communication.

\section{SAFETY AND SECURITY}

With reference to IEC/TS 62443-1-1, the term "security" is considered here to mean the prevention of illegal or unwanted penetration, intentional or unintentional interference with the proper and intended operation, or inappropriate access to confidential information in IACS ( Industrial Automation and Control Systems). Safety requirements are covered e.g. generically with IEC 61508, DIN EN ISO 13849-1 or product respectively application related to DIN EN ISO 16092 (Pressen), EN 62061.

While on shop flow level and non real time applications, those solutions already exist (Figure 3 ), for more demanding requirements, at least in industrial automation, these solutions are not wide spread.

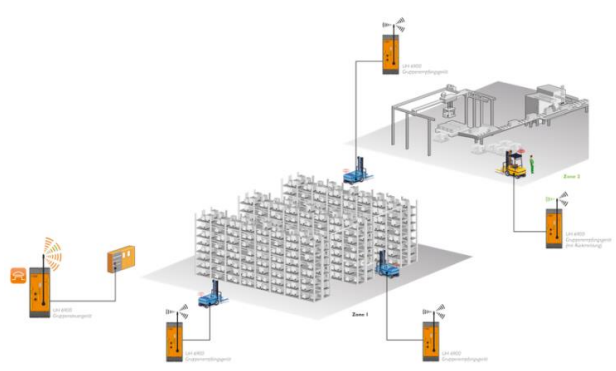

Figure 5: Dold Safemaster W illustration / FTS application example 


\section{PERFORMANCE NEEDS BY SPECIFIC TASK}

Solutions or applications e.g. monitoring of oil cleanliness, power consumption, or data management and trend analysis, could based solutions are already implemented. Following minimum requirements, even under best conditions only lead to ten times less performing installations.

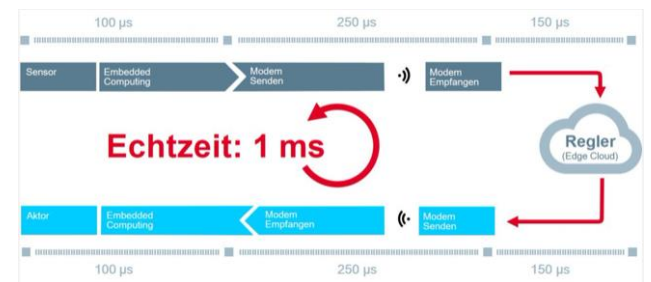

Figure 6: Best case cycle time for $5 \mathrm{G}$ based cloud control. [1]

\section{CONCLUSION AND OUTLOOK}

For the time being, cloud based installation and even edge computing will not fulfil the demanding requirements of real time hydraulic control circuits like dynamic hydraulic valves or electrohydraulic pump controls with pressure and flow control. They are for sure an upcoming solution especially for condition-monitoring ore even cloud based services on data interpretation.

\section{REFERENCES}

[1] https://www.oup-fluidtechnik.de/der-einflussvon-5g-auf-elektrohydraulische-regelungen/ 